\title{
Segundo volume das obras \\ científicas de Mario Schönberg
}

Silvio R. A. Salinas ${ }^{I}$

$\mathrm{H}$ Á CERCA de três anos, por iniciativa da minha colega Amélia Império Hamburger, a Edusp publicava o primeiro volume das "obras científicas" de Mario Schönberg, que foi professor pioneiro da USP e decano dos físicos teóricos brasileiros. Esse primeiro volume continha artigos científicos publicados por Schönberg entre 1936 e 1948, acompanhados de extenso prefácio introdutório escrito por Amélia. A fase inicial dos artigos desse período corresponde a trabalhos de formação, sob a influência de Gleb Wataghin e da primeira visita de Schönberg à Europa. Pouco mais tarde surgem trabalhos em colaboração com pesquisadores eminentes (Chandrasekhar, Gamow) e as primeiras colaborações com os físicos do "grupo de São Paulo" (Occhialini, Abrahão de Moraes, Schützer, Leite Lopes, Cesar Lattes).

Nesse segundo volume das obras científicas estão incluídos os artigos da maturidade. Schönberg trabalha na Bélgica, entre 1948 e 1953, associado ao Centro de Pesquisas Nucleares da Universidade Livre de Bruxelas, publicando principalmente na revista italiana Il Nuovo Cimento. Grande parte dos artigos dessa época, incluindo uma investigação extensa sobre a "radiação de Cerenkov", refere-se a problemas da física dos raios cósmicos, tema central de colaborações com Connie Dilworth e Giuseppe Occhialini. Nesse período ele também publica investigações sobre problemas fundamentais de mecânica quântica e uma série de artigos, particularmente pionei- ros, sobre a formulação da mecânica estatística clássica em termos da "segunda quantização", ou representação da mecânica quântica no espaço de Fock. Voltando ao Brasil, dedica-se à investigação das relações entre "mecânica quântica e geometria", com uma série de artigos publicados nos anais da Academia Brasileira de Ciências. Há grande originalidade nessas tentativas de unificação da mecânica quântica com o eletromagnetismo maxwelliano e a gravitação de Einstein, baseadas nas propriedades geométricas do espaço-tempo, expressas em termos de estruturas algébricas. Schönberg era um excelente físico-matemático para lidar com questões desse tipo, mas essa unificação é um problema difícil não resolvido. Tenho a impressão de que os maiores sucessos da física contemporânea caminharam em outra direção, possibilitando a unificação da mecânica quântica e do eletromagnetismo com as interações fracas e fortes. Ainda não há consenso sobre a forma de incluir a gravitação nesse grande cenário unificador.

Além dos artigos em revistas científicas especializadas, de 1949 a 1977, decidimos incluir nesse volume alguns artigos publicados em anais de conferências. Schönberg foi convidado para falar em um evento de prestígio, organizado em 1958 pela Sociedade Alemã de Física para comemorar os cem anos de nascimento de Max Planck. Um resumo das investigações sobre "mecânica quântica e geometria" apareceu mais tarde nos anais desse evento, que foram 


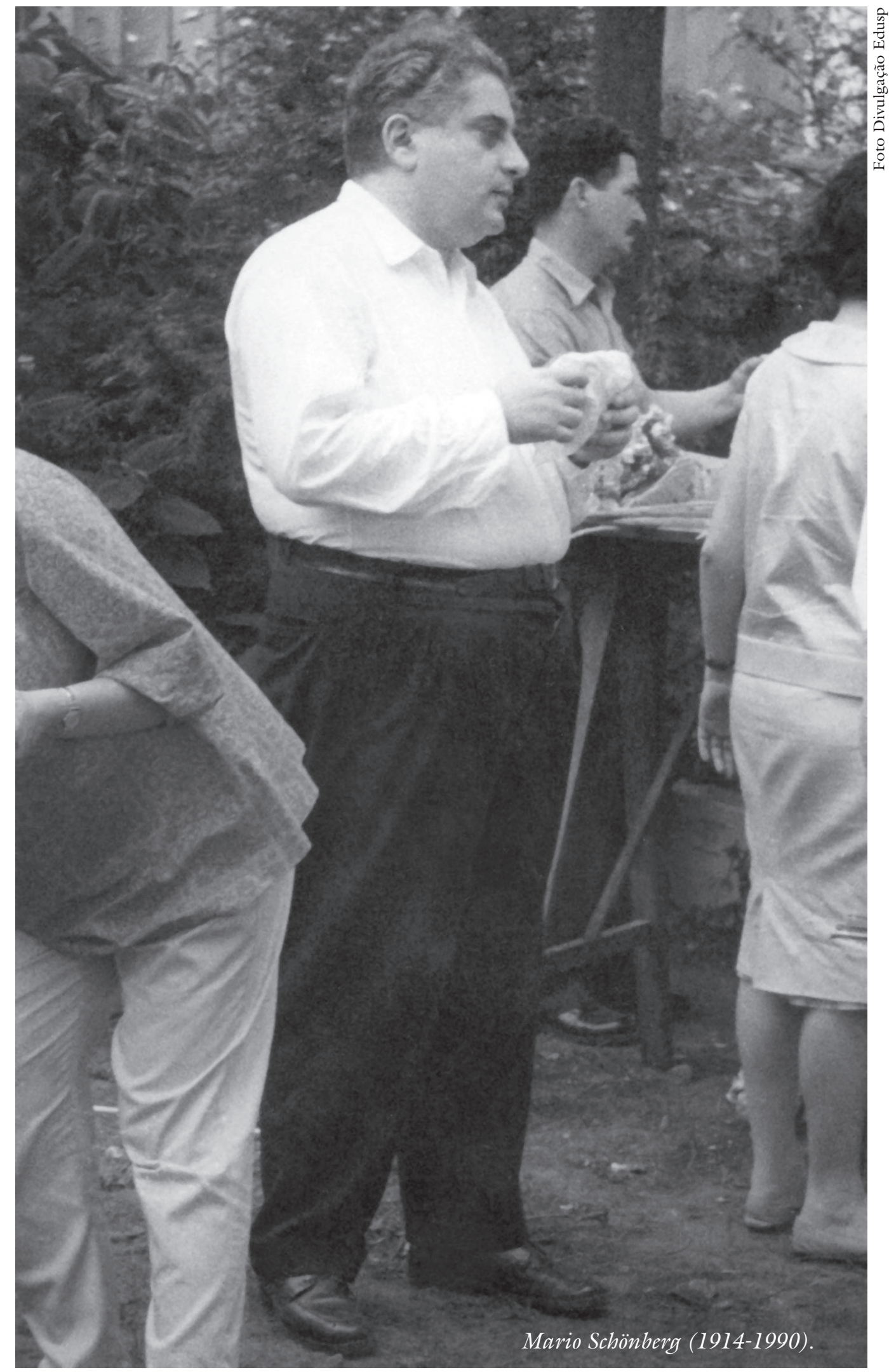


publicados na forma de livro. Embora com dificuldades para viajar, conseguiu participar dos últimos dias de uma conferência realizada em 1965, em Kyoto, em homenagem à proposta do méson de Yukawa. Os anais dessa conferência trazem o seu artigo sobre a "natureza geométrica da carga elétrica e do isospin”, com alguns comentários, numa época em que a unificação já caminhava em outra direção. Incluímos também um artigo póstumo, sobre estruturas algébricas, publicado em volume de anais de conferência especializada, editado pelo matemático Artibano Micali. Sugiro que a leitura desse segundo volume seja iniciada pelos textos finais em português, bem mais acessíveis: "Einstein e a Relatividade Restrita", escrito em comemoração aos cem anos do nascimento de Einstein, e "Eletromagnetismo sem Métrica”, incluído por Alberto Rocha Barros nos anais do simpósio realizado no Ifusp em homenagem aos setenta anos de Mario Schönberg.

Infelizmente Amélia ficou doente e faleceu antes de terminar a edição desse segundo volume. Todos os artigos publicados em revistas científicas, de 1949 a 1977, já tinham sido selecionados e a transcrição digital já estava praticamente completa. Decidi excluir trabalhos em versão preliminar, publicados pelo Centro de Pesquisas Nucleares de Bruxelas, que depois apareceram em versão final na Il Nuovo Cimento. Em contrapartida, incluí artigos publicados em anais de conferências, entre 1959 e 1987, além do artigo póstumo, que apareceu em 1992. De acordo com os procedimentos adotados na edição do primeiro volume, os textos foram organizados com formatação própria e uniforme, digitados em linguagem TEX, a partir de originais publicados em diversos formatos, muitas vezes de acesso complicado. No início desse projeto nem era possível utilizar dispositivos para o reconhecimento óptico dos textos originais. Foram mantidas todas as informações contidas nos originais, com a atualização ortográfica do português e pouquíssimas correções, sem alterar o estilo do autor. Decidi continuar adotando uma notação unificada para os títulos e referências bibliográficas, em consonância com o estilo adotado no primeiro volume. Embora haja indicações de que a própria família tenha achado estranho, decidi manter a "grafia alemã" que Mario Schönberg sempre adotou em todos os seus artigos científicos, inclusive nas publicações científicas brasileiras. A grafia "Schenberg", no entanto, aparece em alguns anais de reuniões no país (e no trabalho póstumo).

Os agradecimentos aos colegas e organizações que permitiram a edição dessas “obras científicas” já foram devidamente registrados por Amélia no prefácio do primeiro volume. Esse trabalho de edição se iniciou há mais de dez anos como um projeto no Instituto de Estudos Avançados da USP (IEA-USP), teve apoio da Fapesp e da direção da Edusp, e foi realizado na sua maior parte com o apoio do Departamento de Física Geral do Ifusp, FGE/Ifusp. A digitação dos originais desse segundo volume foi um trabalho competente, que se deve principalmente a Silvana Maria Ramos de Oliveira, secretária do FGE/Ifusp. O trabalho árduo de correção das primeiras provas de digitação, a partir de originais muitas vezes um tanto precários, foi realizado pelos meus colegas Mário José de Oliveira, do FGE/Ifusp, e Masayuki Oka Hase, da EACH/USP. Sem o trabalho de Mário e de Masayuki, e o 


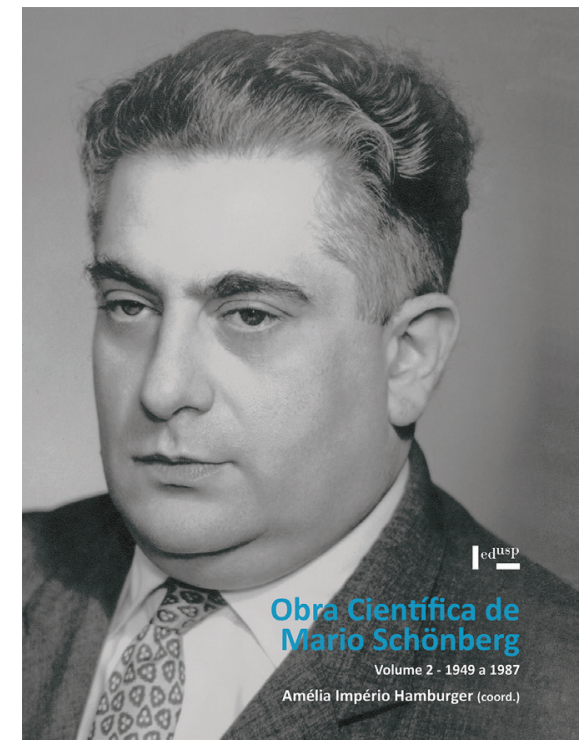

SHÖNBERG, M. Obra cientifica de Mario

Schönberg. Coord. Amélia Império

Hamburger. São Paulo: Edusp,

2013. v.2: 1949 a 1987. 808p.

incentivo do meu colega Ernst Hamburger, eu certamente não teria conseguido completar a edição desse segundo volume das obras científicas do professor Mario Schönberg.

Silvio R. A. Salinas é professor do Instituto de Física da USP. @ - ssalinas@if.usp.br

I Instituto de Física, Universidade de São Paulo/SP, Brasil. 